\title{
Malignant Brenner Tumor of the Ovary: One Single Institute Experience and a Review of the Literature
}

\author{
Malek Bouhani, (D) Maher Slimane, (1) Sarah Sghaier, (D) Amine Bouida, (1) Riadh Chargui, \\ (D) Khaled Rahal
}

Department of Oncologic Surgery, Salah Azaiz Institute, Tunis, Tunisia

\section{ABSTRACT}

Objectives: Malignant Brenner tumors (MBT) of the ovary are rare diseases, representing $1 \%$ of all ovarian cancers and 3-5\% of Brenner tumors. They carry a poor prognosis. They generally affect women during the perimenopausal and postmenopausal periods. The standard treatment is surgery; however, the indication of adjuvant chemotherapy remains controversial. The present study aims to report our experience in the treatment of MBT of the ovary, to better characterize this disease.

Methods: In this study, a retrospective case series involving four patients diagnosed with MBT of the ovary and treated between 2006 and 2014.

Results: Four cases of MBT of the ovary were diagnosed over a seven-year period. The mean age of our patients was $59.3 \pm 11.1$ years. Three patients were in the menopause period. The tumor was staged as IC in one case, IIC in one case, and IIIC in two cases of the International Federation of Gynecology and Obstetrics classification. All patients underwent surgery, followed by adjuvant chemotherapy. Three patients underwent a loco-regional recurrence that occurred respectively, after nine months in one patient and 11 months in two patients. The treatment was based on chemotherapy combined with surgery in one case. Two patients presented distant metastasis. The treatment consisted of chemotherapy and surgery. The median follows up period was 49.0 (14.0-64.0) months.

Conclusion: The treatment approach of MBT of the ovary is not well established since its scarcity and poor prognosis. Thus, more case series and meta-analysis should be conducted.

Keywords: Brenner tumor, ovary, lymph node excision, prognosis, Operative surgical procedure

Dr. Malek Bouhani. Departh

of Oncologic Surgery, Salah

Azaiz Institute, Tunis, Tunisia

Phone: +90 21623604048

E-mail:

bouhani_malek@hotmail.fr

Received Date: 06.06.2019

Accepted Date: 28.08.2019

Published online: 01.04 .2020

(C) Copyright 2020 by Anatolian Journal of Family Medicine -

Available online at

www.anatoljfm.org

OPEN ACCESS

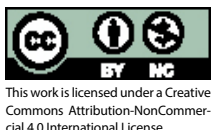

\section{INTRODUCTION}

Brenner tumors of the ovary are rare, representing $1 \%$ of all ovarian tumors. They are usually benign. ${ }^{[1]}$ Its malignant form has a very low incidence, accounting for 3-5\% of Brenner tumors and less of $1 \%$ of all ovarian malignancies. ${ }^{[2-4]}$ Malignant Brenner tumors (MBT) of the ovary have a poor prognosis. ${ }^{[5,6]}$ They generally occur in women during the perimenopausal and postmenopausal periods. ${ }^{[7]}$

Surgery constitutes the standard of treatment for MBT as for the other epithelial ovarian tumors. ${ }^{[8]}$ The place of adjuvant chemotherapy remains controversial. ${ }^{[9,10]}$ The present study aims to report our experience withthe treatment of this rare entity and to discuss the best way of care with a critical review of the literature. 


\section{METHOD}

A retrospective case series involving four patients diagnosed with MBT of the ovary and treated between 2006 and 2013 involved in this report. The International Federation of Gynecology and Obstetrics classification 2014 ovarian cancer classification was assigned for each case. The pathological diagnosis was made according to the criteria established by Hull and Campbell.

According to the decision of a multidisciplinary meeting, the most suitable treatment regimen was offered to each woman. Follow up findings were retrospectively collected from medical files.

Frequencies, percentage, mean, standart deviation, median, minimum, and maximum were used for descriptive statistical methods.

\section{RESULTS}

Four cases of MBT of the ovary were diagnosed over a seven-year period. The demographic and pathologic characteristics are shown in Table 1. The mean age of our patients was $59.3 \pm 11.1$ years. None of the cases presented with vaginal bleeding. All the tumors were viewed by ultrasound imaging and presented with solid and cystic components together with a predominance of the solid contingent. Three of them were located in the left ovary and the fourth in the right one. The mean size was $12.5 \pm 4.8 \mathrm{~cm}$. Ascites were detected in all patients. The tumor marker CA 125 was high in three patients and normal in one patient.

All patients underwent a staging surgery, including hysterectomy, bilateral adnexectomy, appendectomy, omentectomy, and peritoneal cytology and biopsies. In three patients, it persisted millimetric nodules of carcinomatosis. The fourth patient did not have nodules of carcinomatosis left, so she underwent pelvic and aortic lymphadenectomy.

In all patients, the contralateral ovary was macroscopically normal. In the histologic results, two patients had bilateral MBT. Macroscopically, they had a grayish aspect and were voluminous. In fact, the median size in the histologic examination was $12.0(8.0-18.0) \mathrm{cm}$.

The microscopy findings showed a multi-layered atypical transitional cell epithelium. The cells were arranged in papillae with atypical nuclei within a fibrous stroma. There were abundant mitosis and a stromal invasion. In addition, we noticed the presence of benign components or borderline Brenner tumors.

The immunohistochemical study was conducted in all cases showing positivity for cytokeratin 7 and vimentin and negativity to cytokeratin 20 .

The stage of the tumor for each patient is summarized in Table 2. In any of these patients, there was no lymph node metastasis detected. Chemotherapy following surgery was indicated in all patients. Three women received six courses of Taxol-Carboplatin. The fourth patient presented a digestive intolerance after four courses of Taxol-Carboplatin. Thus, she received two courses of Endoxan-Carboplatin instead of Taxol-Carboplatine (Table 2).

Patients, who did not undergo pelvic and aortic lymph nodes dissection, underwent completion surgery one month after the end of chemotherapy (3 patients). All lymph nodes were negative in the histologic examination.

During the follow-up, three patients presented with a loco-regional recurrence. However, distant metastasis was detected in two patients. The first patient relapsed with a $3 \mathrm{~cm}$ mass in the pouch of Douglas. However, given the advanced age of the patient, we decided to offer her symptomatic treatment. The first patient did not present any distant metastasis.

The second patient relapsed with a $10 \mathrm{~cm}$ mass in the prevesical peritoneum. She was treated with six courses of well-tolerated Gemzar-Adriamycin chemotherapy. However, she presented multiple liver metastasis and abdominal carcinomatosis after 20 months. Then, she received six courses of Taxol every week but with no response demonstrated in the computed tomography scanning.

Table 1. Features of patients

\begin{tabular}{lcccccc} 
Case & Age & Parity & Menopause & Symptoms & CT: size (cm)/side & CA125 U/ml \\
\hline 1 & 73 & 1 & Yes & Abdominal distension & $15 /$ left & 294 \\
2 & 46 & 6 & No & Abdominal pain & $9 /$ left & 490 \\
3 & 60 & 4 & Yes & Pelvic mass & $8 /$ right & 273.4 \\
4 & 58 & 8 & Yes & Pelvic pain & 18/left & $\mathrm{NI}$ \\
\hline
\end{tabular}

NI: normal. CA125 cut off level: $35 \mathrm{U} / \mathrm{ml}$. CT: Computed tomography. TM: Tumor marker. 
Table 2. Outcomes of patients

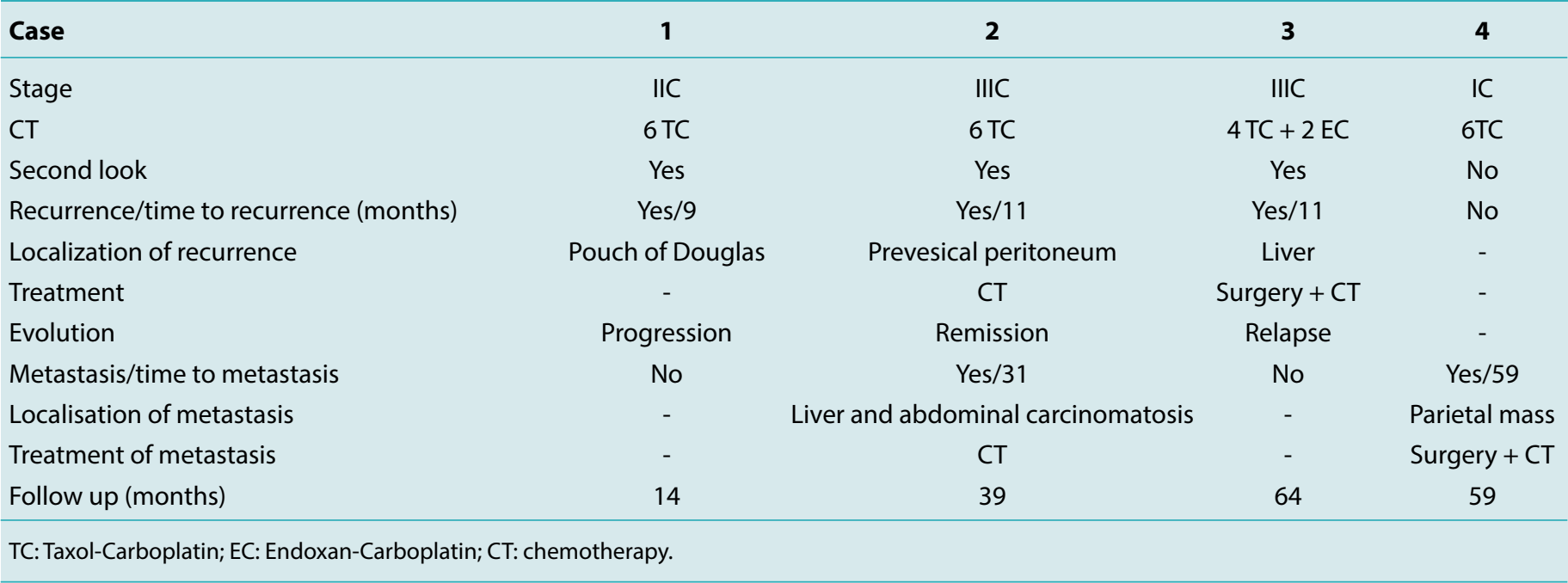

The third patient relapsed after 11 months in the liver. She was treated by four courses of Taxol-Carboplatin with a partial decrease in the volume of the liver mass. Then, she underwent surgery where the mass was dissected and fully removed. Secondly, after seven months following the first relapse, she presented abdominal carcinomatosis to which she received symptomatic treatment.

The fourth woman presented a $5 \mathrm{~cm}$ subcutaneous parietal mass after 59 months. A mass resection was performed followed by Taxol-Carboplatin, but the patient was lost after the first course. The patients were followed up by tumor markers, ultrasonography and/or computed tomography scanning. The median follows up period was 49.0 (14.064.0) months.

\section{DISCUSSION}

Brenner tumors of the ovary are rare and usually benign. ${ }^{[1]}$ Its malignant form represents an uncommon disease, accounting for $1 \%$ of all ovarian cancers and 3-5\% of Brenner tumors. ${ }^{[1,3,4]}$

MBT of the ovary carries a poor prognosis. ${ }^{[5,6]}$ However, in a previous study, it has been shown that MBT has a better prognosis than the other epithelial ovarian cancers. ${ }^{[6]}$ They are most commonly diagnosed in women during the perimenopausal and postmenopausal periods. ${ }^{[7]}$

Clinical manifestation of MBT is comparable to that of other epithelial ovarian neoplasms. The main clinical symptom is abdominal distension or pain. ${ }^{[11]}$ However, some may complain about pelvic pain or mass or postmenopausal bleeding. ${ }^{[1,8,12]}$

There are no specific ultrasound features for MBT. However, they usually presented with a large size and an admixture of solid and cystic components. ${ }^{[11]}$ Typically, MBT is bilateral contrary to benign forms. ${ }^{[13]}$

There is no specific tumor marker for MBT. ${ }^{[14,15]}$ However, a high level of CA 125 can predict the malignant form of the tumor, ${ }^{[16]}$ but as we reported in the fourth case, the CA 125 was normal.

Initially, these tumors were known as Transitional-Cell Carcinoma of the Ovary (TCCO). ${ }^{[1]]}$ Then, later studies and the revised World Health Organization ovarian tumor classification confirmed that MBT forms a distinct histological subgroup of epithelial ovarian tumors. ${ }^{[3,4,12,17-19]}$ Moreover, TCCO includes Brenner tumors, which can be benign, borderline, or malignant and non-Brenner TCCO type. ${ }^{[20]}$

In addition to that, histopathological diagnosis was confirmed using the criteria described by Hull and Campbell, which added the stromal invasion to Idelson's criteria. ${ }^{[4,21-23]}$ The latter ones included malignant histological features, the presence of a benign component or Borderline Brenner tumors and exclusion of a pseudomucinous cystadenoma, a teratoma or metastasis from a urinary tract tumor.

Histopathological findings are similar to the findings of the present study. In fact, they described MBT as voluminous tumors with a greyish aspect macroscopically. ${ }^{[20]}$ They are characterized by an atypical transitional cell epithelium similar to the urothelium. ${ }^{[1]}$ In addition, arranged cells papillae with atypical nuclei within a fibrous stroma areusually noticed. There are also abundant mitosis and a stromal invasion. ${ }^{[20]}$

The immunohistochemistry findings demonstrated posi- 
tivity for CK7, CK13, uroplakin III thrombomodulin, GATA3, S100 and negativity for cytokeratin $20 .{ }^{[1,18,19,24]}$

Surgery is the cornerstone of the treatment of women with MBT. ${ }^{[7]}$ Similar to other epithelial ovarian neoplasms, the surgical procedure consists of a hysterectomy, salpingooophorectomy, omentectomy, appendectomy with or without pelvic and para-aortic lymphadenectomy. ${ }^{[25]}$ In fact, the lymphatic spread pattern is not known. ${ }^{[11]}$ Furthermore, it has been shown that among women who had conducted lymph node sampling, 5\% presented metastatic lymph nodes. ${ }^{[11]}$ In addition to that, Nasioudis et al. concluded that Disease-Specific Survival did not differ among patients who underwent lymphadenectomy and patients who did not. ${ }^{[1]]}$ In contrast, overall survival was higher in the group that underwent lymph node staging. ${ }^{[1]}$

Consequently, the benefit of lymphadenectomy is not well established, which leads to discussing the feasibility of sentinel lymph node in MBT. ${ }^{[3,26]}$

The administration of adjuvant chemotherapy is not clearly demonstrated. In fact, the Surveillance Epidemiology and End Results database does not elucidate details about the different drugs and doses available in the treatment of this rare disease. ${ }^{[1]}$ However, some studies noticed a complete response after adjuvant chemotherapy.

Platini et al. conducted a study in 1992 and noticed a complete histologic response in two patients with stage IIIC. The first woman received six courses of cyclophosphamide cisplatinum chemotherapy and the second woman was treated by cyclophosphamide, carboplatin, and doxorubicin. ${ }^{[16]}$ Similarly, Gezging et al. demonstrated a complete response when using Carboplatin-Taxol chemotherapy with nine patients out of $10 .{ }^{[1]}$ In the same light, Han et al. showed a total response in all patients who received the taxol- carboplatin regimen. ${ }^{[8]}$

Concerning the dissemination of MBT of the ovary, it is usually locoregional and causing infrequent distant metastasis. ${ }^{[27,28]}$ However, the outcomes of our study demonstrate exceptional metastasis.

It has been shown that $80 \%$ of MBT of the ovary are diagnosed in stage I and characterized with an excellent prognosis and a five-year survival estimated at $88 \%\left[{ }^{[7,20]}\right.$ In contrast, advanced stages of MBT carry a poor prognosis with a five-year survival not exceeding $40 \% .{ }^{[29]}$ Correspondingly, Nasioudis et al. noticed that the survival of women with the extra-ovarian stage is similar to other epithelial ovarian neoplasms. ${ }^{[11]}$
Many authors reported locoregional recurrence and distant metastasis during follow up..$^{[1,8,11]}$

In the previous studies, as in our present cases, favorable results were noted with chemotherapy in the treatment of recurrent cases. ${ }^{[1,11]}$ Thus, the treatment of MBT seems to be a challenging topic,raising the importance of multidisciplinary teams in their management.

\section{CONCLUSION}

MBT isa rare disease with a poor prognosis. The treatment approach is based on surgery. The real benefit of the administration of adjuvant chemotherapy remains debatable. However, due to the scarcity of this disease, more case series and meta-analysis are required to back-up our findings and give an adequate recommendation in the therapeutic management of MBT.

\section{Disclosures}

Peer-review: Externally peer-reviewed.

Conflict of Interest: None declared.

Informed consent: Written informed consent was obtained from the patient for the publication of the case report.

Authorship Contributions: Concept - M.B.; Design - R.C.; Supervision - K.R.; Materials - M.S.; Data collection \&/or processing B.A.; Analysis and/or interpretation - S.S.; Literature search - M.B.; Writing - S.S.; Critical review - K.R.

\section{REFERENCES}

1. Gezginç K, Karatayli R, Yazici F, Acar A, Çelik Ç, Çapar M, et al. Malignant Brenner tumor of the ovary: analysis of 13 cases. Int J Clin Oncol 2012;17:324-9. [CrossRef]

2. Roth LM, Dallenbach-Hellweg G, Czernobilsky B. Ovarian Brenner tumors. I. Metaplastic, proliferating, and of low malignant potential. Cancer 1985;56:582-91.[CrossRef]

3. Ali RH, Seidman JD, Luk M, Kalloger S, Gilks CB.Transitional cell carcinoma of the ovary is related to high-grade serous carcinoma and is distinct from malignant brenner tumor. Int J Gynecol Pathol 2012;31:499-506. [CrossRef]

4. Kurman RJ, Carcangiu ML, HerringtonCS, Young RH. World Health Organisation Classification of Tumours of the Female Reproductive Organs. 4th ed. International Agency for Research on Cancer; 2014.

5. Balasa RW, Adcock LL, Prem KA, Dehner LP. The Brenner tumor: a clinicopathologic review. Obstet Gynecol 1977;50:120-8.

6. Roth LM, Gersell DJ, Ulbright TM. Ovarian Brenner tumors and transitional cell carcinoma: recent developments. Int J Gynecol Pathol 1993;12:128-33. [CrossRef]

7. Mena LM, Carmona E, Maza FR, Guiote MV, Moreno E, Vallejo JA. Malignant ovarian Brenner tumor. A case report evalu- 
ated with 18F-FDG PET/CT. Rev Esp Med Nucl Imagen Mol 2015;34:337-8. [CrossRef]

8. Han JH, Kim DY, Lee SW, Park JY, Kim JH, Kim YM, et al. Intensive systemic chemotherapy is effective against recurrent malignant Brenner tumor of the ovary: An analysis of 10 cases within a single center. Taiwan J Obstet Gynecol 2015;54:178-82.

9. Ballard KS, Thurston BC, Sennett MD, Tedjarati SS. A rare malignant Brenner tumor of the ovary in a 77-year-old woman: a case report. J Reprod Med 2009;54:517-9.

10. Driss M, Mrad K, Dhouib R, Doghri R, Abbes I, Ben Romdhane K. Ascitic fluid cytology in malignant Brenner tumor. Acta Cytol 2010;54:598-600. [CrossRef]

11. Nasioudis D, Sisti G, Holcomb K, Kanninen T, Witkin SS. Malignant Brenner tumors of the ovary; a population-based analysis. Gynecol Oncol 2016;142:44-9. [CrossRef]

12. Austin RM, Norris HJ. Malignant Brenner tumor and transitional cell carcinoma of the ovary: a comparison. Int J Gynecol Pathol 1987;6:29-39. [CrossRef]

13. Hermanns B, Faridi A, Rath W, Füzesi L, Schröder W. Differen-tial diagnosis, prognostic factors, and clinical treatment of proliferative Brenner tumor of the ovary. Ultrastruct Pathol 2000;24:191-6. [CrossRef]

14. Seldenrijk CA, Willig AP, Baak JP, Kühnel R, Rao BR, Burger CW, et al. Malignant Brenner tumor. A histologic, morphometrical, immunohistochemical, and ultrastructural study. Cancer 1986;58:754-60. [CrossRef]

15. Yamamoto R, Fujita M, Kuwabara M, Sogame M, Ebina $Y$, Sakuragi $N$, et al. Malignant Brenner tumors of the ovary and tumor markers. Jpn J Clin Oncol 1999;29:308-13. [CrossRef]

16. Platini C, Weber B, Conroy T, Ennen-Simard MJ. Chemotherapy of malignant ovarian Brenner tumors. Review of the literature apropos of 2 histological complete remissions after polychemotherapy. Bull Cancer 1992;79:963-7.

17. Cuatrecasas M, Catasus L, Palacios J, Prat J. Transitional cell tumors of the ovary: a comparative clinicopathologic, immunohistochemical, and molecular genetic analysis of Brenner tumors and transitional cell carcinomas. Am J Surg Pathol 2009;33:556-67. [CrossRef]

18. Riedel I, Czernobilsky B, Lifschitz-Mercer B, Roth LM, Wu XR, Sun $T$, et al. Brenner tumors but not transitional cell carcinomas of the ovary show urothelial differentiation: immunohistochemical staining of urothelial markers, including cytokeratins and uroplakins. Virchows Arch 2001;438:181-91.

19. Logani S, Oliva E, Amin MB, Folpe AL, Cohen C, Young RH. Im- munoprofile of ovarian tumors with putative transitional cell (urothelial) differentiation using novel urothelial markers: histogenetic and diagnostic implications. Am J Surg Pathol 2003;27:1434-41. [CrossRef]

20. El Youbi MB, M'rabti H, Mohtaram A, Aaribi I, Kharmoum J, El Khannoussi $B$, et al. Tumeur de Brenner maligne avec très bonne réponse après chimiothérapie: à propos d'un cas et revue de la littérature [Malignant Brenner tumor with very good response after chemotherapy: about a case and review of the literature]. Pan Afr Med J 2014;17:293. [CrossRef]

21. Hull MG, Campbell GR. The malignant Brenner tumor. Obstet Gynecol 1973;42:527-34. [CrossRef]

22. Meinhold-Heerlein I, Fotopoulou C, Harter P, Kurzeder C, Mustea A, Wimberger $\mathrm{P}$, et al. The new WHO classification of ovarian, fallopian tube, and primary peritoneal cancer and its clinical implications. Arch Gynecol Obstet 2016;293:695-700.

23. IDELSON MG. Malignancy in Brenner tumor of the ovary, with comments on histogenesis and possible estrogen production. Obstet Gynecol Surv 1963;18:246-67. [CrossRef]

24. Esheba GE, Longacre TA, Atkins KA, Higgins JP.Expression of the urothelial differentiation markers GATA3 and placental S100 (S100P) in female genital tract transitional cell proliferations. Am J Surg Pathol 2009;33:347-53. [CrossRef]

25. Verleye L, Ottevanger PB, van der Graaf W, Reed NS, Vergote I; Gynaecological Cancer Group (GCG) of European Organisation for Research and Treatment of Cancer (EORTC). EORTCGCG process quality indicators for ovarian cancer surgery. Eur J Cancer 2009;45:517-26. [CrossRef]

26. Rouzier R, Bergzoll C, Brun JL, Dubernard G, Selle F, Uzan S, et al. The role of lymph node resection in ovarian cancer: analysis of the Surveillance, Epidemiology, and End Results (SEER) database. BJOG 2010;117:1451-8. [CrossRef]

27. Oh SN, Rha SE, Jung SE, Lee YJ, Choi BG, Byun JY, et al. Transitional cell tumor of the ovary: computed tomographic and magnetic resonance imaging features with pathological correlation. J Comput Assist Tomogr 2009;33:106-12.[CrossRef]

28. Ben Aissia N, Sadfi A, Youssef A, El Ayeb A, Chadli A, Mzabi R, et al. Malign Brenner's tumor particularities and coverage. Tunis Med 2004;82:701-7.

29. van der Weiden RM, Gratama S. Proliferative and malignant Brenner tumours (BT) and their differentiation from metastatic transitional cell carcinoma of the bladder: a case report and review of the literature. Eur J Obstet Gynecol Reprod Biol 1987;26:251-60. [CrossRef] 